\title{
Manufacturing technologies and joining methods of metallic thin-walled pipes for use in high pressure cooling systems
}

\author{
Sophie A. M. McNair ${ }^{1}$ (D) Alborz Shokrani Chaharsooghi ${ }^{1} \cdot$ Mauro Carnevale $^{1} \cdot$ Andrew Rhead $^{1} \cdot$ Antti Onnela $^{2}$. \\ Jerome Daguin ${ }^{2} \cdot$ Kamil Cichy $^{2} \cdot$ Hans Postema $^{3} \cdot$ Nicola Bacchetta $^{2} \cdot$ Thomas French $^{2} \cdot$ Alexander J. G. Lunt $^{1}$
}

Received: 19 May 2021 / Accepted: 27 August 2021 / Published online: 7 September 2021

(C) The Author(s) 2021

\begin{abstract}
Small diameter thin-walled pipes, typically with a diameter less than $20 \mathrm{~mm}$ and a ratio of outer diameter to wall thickness is 20 or above, have increasingly become a key value adding factor for a number of industries including medical applications, electronics and chemical industries. In high-energy physics experiments, thin-walled pipes are needed in tracking detector cooling systems where the mass of all components needs to be minimised for physics measurement reasons. The pipework must reliably withstand the cooling fluid operation pressures (of up to 100 bar), but must also be able to be reliably and easily joined within the cooling system. Suitable standard and/or commercial solutions combining the needed low mass and reliable high-pressure operation are poorly available. The following review of literature compares the various techniques that exist for the manufacture and joining of thin-walled pipes, both well-established techniques and novel methods which have potential to increase the use of thin-walled pipes within industrial cooling systems. Gaps in knowledge have been identified, along with further research directions. Operational challenges and key considerations which have to be identified when designing a system which uses thin-walled pipes are also discussed.
\end{abstract}

Keywords Thin-walled pipes $\cdot$ Joining techniques $\cdot$ Pipe manufacture $\cdot$ High pressure cooling systems

\section{Introduction}

The use of small diameter, thin-walled pipes has increased dramatically over recent years. As manufacturing processes for the production of miniature components has improved, this has facilitated the production of components with tighter tolerances and smaller dimensions. In particular, thin-walled metallic pipes have allowed for greater innovation in the design of components for a number of industries including particle physics, nuclear, medical and communications. As such, they have become a crucial value adding factor, and an area of increasing interest for further research into novel

Sophie A. M. McNair

samw20@bath.ac.uk

1 Department of Mechanical Engineering, The University of Bath, Claverton Down BA2 7AY, UK

2 CERN, Geneva, Switzerland

3 Department of Physics, Cornell University, Ithaca, NY 14850, USA manufacturing techniques and the miniaturisation of well-established pipe forming processes as highlighted by [1]

Commonly, thin-walled pipes are defined when the ratio of the outer diameter to minimum wall thickness is greater than $20\left(\mathrm{~d}_{\mathrm{o}} / \mathrm{t}_{\min }>20\right)$ [2]. This is when the differences in the hoop stresses at the inner and outer pipe surfaces become negligible are often ignored. When discussing thin-walled pipes, the term pipe and tube are often used interchangeably; however, there is a subtle difference between the two terms defined by pipe manufacturers. A pipe is defined in terms of its inner diameter whereas a tube is defined by its outer diameter. Thin-walled pipes are generally described by their outer diameter $\left(d_{o}\right)$ and wall thickness $\left(t_{\mathrm{w}}\right)$ and therefore conventionally the term tube would in fact be more appropriate.

Hartl [1] neatly summarises the typical industries and applications where thin-walled pipes are commonly used as detailed in Table 1.

This paper investigates state-of-the-art technologies for the manufacture and joining of metallic thin-walled pipes within the literature. The use of such pipes in high-performance cooling systems has been chosen as a particular area of interest as this is a significant area of growth for thin-walled pipes. 
Table 1 Summary of thin-walled pipe industrial uses and applications [1]

\begin{tabular}{lll}
\hline Industries which utilise thin-walled pipes & Typical products & Materials used in products \\
\hline Medical applications & Injection needles & Stainless steel \\
& Catheters & Titanium alloys \\
& Stents & Magnesium alloys \\
Electronic and electrical engineering & Contact probes & Nickel alloys \\
& Electrode tubes for EDM & Copper alloys \\
Optoelectronics & Optical fibres & Nickel alloys \\
& Laser accelerators & Kovar \\
Chemical processing technologies & Micro-reactors & Stainless steel \\
& Micro-nozzles & Titanium alloys \\
Sensing technologies & Differential gas pressure detector & Platinum alloys \\
Heat transfer applications & Micro-quantitative analysis device & Tungsten alloys \\
& Micro-heat exchangers & Titanium alloys \\
& & Aluminium alloys \\
\hline
\end{tabular}

\section{High pressure cooling systems}

A good example of where thin-walled pipes are vital is in the use of high pressure refrigeration systems, such as two-phase $\mathrm{CO}_{2}$ cooling. $\mathrm{CO}_{2}$ is a particularly attractive refrigerant as it is a non-toxic, non-flammable gas that does not contribute to ozone depletion [3] and is significantly cheaper than fluorocarbons. Two-phase $\mathrm{CO}_{2}$ cooling exploits the latent heat change of the liquid to gas transition in order to generate a cooling effect. $\mathrm{CO}_{2}$ has other advantages over fluorocarbons such as a high latent heat of evaporation, lower viscosity and a higher heat transfer coefficient [4]. However, in comparison with fluorinated systems, two-phase $\mathrm{CO}_{2}$ cooling requires the use of high-pressure tubes and compressors (up to 130 bar design pressure) [5]. To facilitate these pressures, very small diameter pipes are favoured in such systems.

These advantages, in addition to small diameter pipes, make two-phase $\mathrm{CO}_{2}$ cooling a very attractive candidate for particle physics detector cooling. The use of small diameter, thin-walled pipes minimises the interaction with tracked particles and therefore increases the resolution of the detector. Pipes with 0.5 to $3.0 \mathrm{~mm}$ inner diameter and 0.10 to $0.25 \mathrm{~mm}$ wall thicknesses are common. Example systems include the two-phase accumulator-controlled loop (2PACL) system used to cool the AMS-tracker and LHCb-Velo detectors [6, 7]. Future systems which are likely to benefit from this type of cooling include detectors for the high luminosity LHC [8], the future circular collider [9] and the CLIC [10], at CERN. In the USA, the PIP-II [11] and LBNF/ DUNE [12] projects at Fermilab will also make use of $\mathrm{CO}_{2}$ cooling. This review is therefore very timely for the experimental particle physics community.

\section{Manufacturing}

The high pressures present in $\mathrm{CO}_{2}$ cooling systems mean that the pipes and connections used in their production need to be of a high strength and must be exceptionally reliable. For example, a leakage would cause the $\mathrm{CO}_{2}$ to escape as gas, which could lead to temperature rises in critical systems due to reduced cooling flow and the potential for asphyxiation. Many of these cooling systems are fully integrated into the design of detectors, and therefore, access is highly restricted or even impossible. For example, the CMS upgrade tracker is being designed for a 10-year operational life with no planned maintenance interventions as highlighted by designs put forward by $[13,14]$.

Generally, pipes used in cooling systems can be classified as seamed or seamless. Seamed pipes are formed from a flat piece of metal and welded or joined in some way along a seam. In contrast, seamless pipes are formed from the bulk material into a tubular shape without welding or joining along the axis. Seamed pipes are prone to failure at the joining line due to the heat affected zone (HAZ), residual stresses and microstructural changes during joining processes. Seamless tubes typically have a strength and microstructure that are more homogeneous according to simulations by [15] which indicates that they have an expected lifetime significantly longer than the equivalent seamed tube. Given that $\mathrm{CO}_{2}$ cooling operates at high pressures which require consistent high strength and in environments with minimal intervention, seamless pipes are the preferred choice.

As in any engineering system, the manufacturing method used to produce a pipe plays a critical role in the performance of the final product. There are many methods currently used for manufacturing thin-walled pipes depending on the material choice, pipe dimensions and performance requirements. In general, seamless pipes are manufactured using a cold 
working process followed by heat treatment to allow good mechanical properties as well as dimensional accuracy [16]. Cold working methods include cold drawing and cold pilgering.

\subsection{Cold drawing}

Cold drawing is the process of extruding a hollow tube by pulling a workpiece through a die, during which the outer diameter of the pipe is dictated by the die dimensions after drawing [17]. The workpiece is generally prepared from an ingot in a hydraulic press. For smaller diameter pipes, this ingot typically starts with a diameter of $40-60 \mathrm{~mm}$ and a wall thickness of 3.5-6 mm [18]. To reduce the diameter and wall thicknesses as required, multiple drawing cycles are performed as the tube reduction ratio is limited to between 2.0 and 2.5 per cycle [18]. This reduction ratio has been shown to prevent damage [19]. The cyclic nature of cold drawing makes it quite a costly process. There is also the potential for numerous intermediate heat treatments or degreasing stages, which also increase the price of the final product [18]. In addition, the flow of material during these processes can lead to the development of preferred orientation within the grains of the metal and anisotropic mechanical properties in the final product $[15,20]$. As such, there is a trade-off between reducing costs by minimising the number of cycles while preventing damage and promoting desirable microstructures of the final product [21].

Toribio and Ovejero [21] studied the effect of cold drawing on high strength steel wire, taking micrographs of the structure before drawing and after each pass, with 6 passes in total reducing the diameter from 12 to $7 \mathrm{~mm}$. Selected micrographs from longitudinal sections can be seen in Figure 1, clearly showing the flow of material during the drawing process.

\subsection{Cold pilgering}

In contrast to cold drawing, cold pilgering uses a pair of rotating dies and a reciprocating mandrel which is located inside the pipe to be extruded and is tapered in the rolling direction as shown in Figure 2. Abe and Furugen [16] indicate that cold

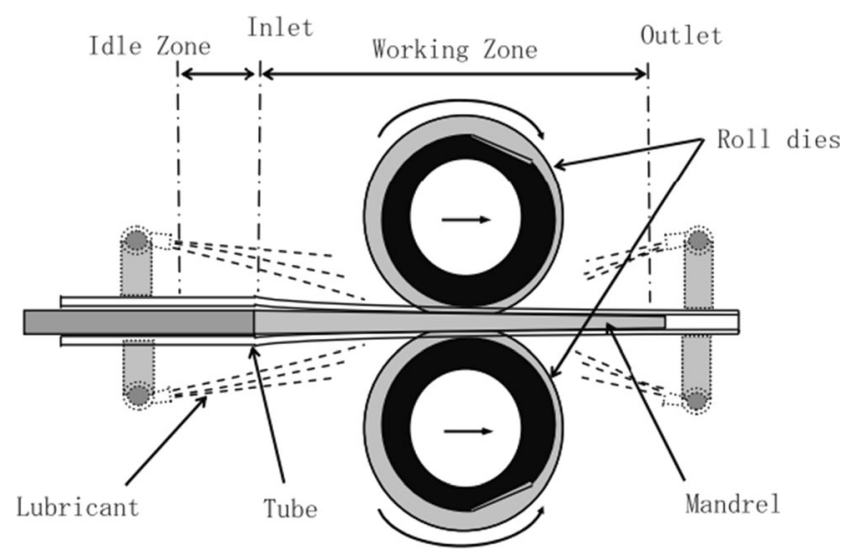

Figure 2 Schematic of a cold pilgering extrusion process [16]

pilgering is suitable for metals that are difficult to deform as the strain rates during the process are smaller than in cold drawing and can be more carefully controlled.

After each forward/backward movement of the dies, the pipe is turned and moved forward for the next step. Typically, around 100 of these steps are necessary to produce the final product [22]. It should be noted that a larger reduction in cross section is possible using cold pilgering compared to cold drawing [23]. The main parameters affecting the deformation are the die rolling rate, the movement of pipe after each step and the geometry of the tools. However, due to the nature of cold pilgering, there are greater stresses generated on the inner wall of the pipe than the outer surfaces during rolling [24] which can cause flattening of the pipe and fissures on the inner surface as indicated by experiments by [16] and other authors. Typically, the grain size resulting from cold drawing and cold pilgering is similar after working, with this variable being primarily dependent upon the subsequent annealing processes [25]

\subsection{Novel processes}

In recent years other, more novel processes have been developed to create thin-walled seamless pipes. Maier et al. [20] demonstrated a cold spray forming process, where stainless steel powder was sprayed onto a rotating aluminium tube to

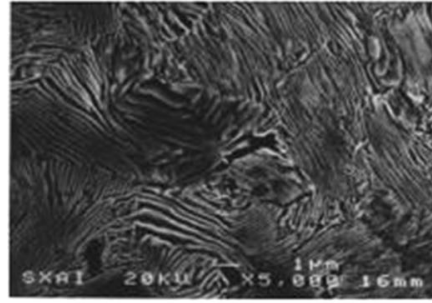

(a) - Structure before cold drawing

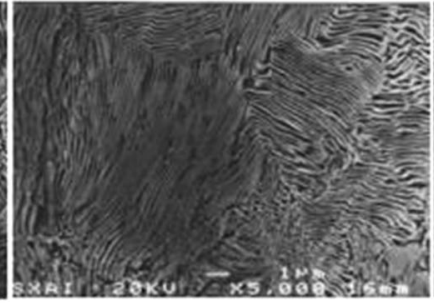

(b) - Structure after 2 passes

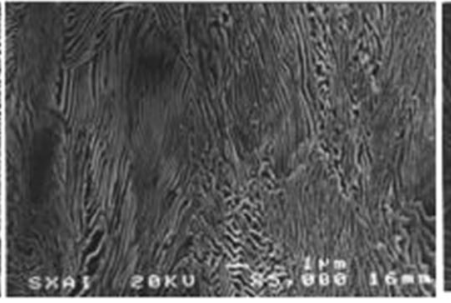

(c) - Structure after 4 passes

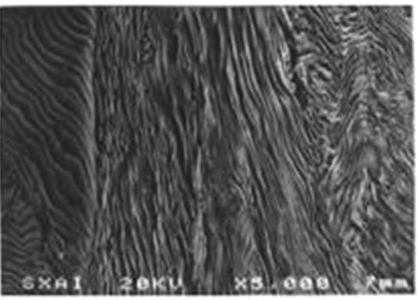

(d) - Structure after 6 passes

Figure 1 Micrographs of structure of steel wire after being subjected to various passes of cold drawing [21] 
create a 1-mm-thick layer of material. The aluminium tube was then dissolved to leave behind a thin-walled stainless-steel pipe. The purpose of this work was to demonstrate a process in which the properties of the resulting pipe could be tailored by altering the phase and composition of powders used as a function of position. This is a promising advancement which can potentially be expanded to other additive manufacture processes aside from cold spray forming. For example, [26] studied pipes created from laser sintered powders. A major advantage of this approach was that complex connections, such as slits or petals, could be directly built onto the end of the pipes using this approach. Despite this, the samples used in this study were relatively short $(106.5 \mathrm{~mm})$ and therefore significant amounts of development are still required to assess the suitability of creating lengths of the order of a few metres required for cooling systems.

While the methods described above are known to be suitable for the production of thin-walled pipes, other manufacturing methods can also produce larger diameter seamless pipes; for example, deep hole drilling. This is a well-established single-step process where a central bore is drilled out along a solid cylindrical part to create a pipe.

Maderbacher et al. completed a study on a large amount (1800) of pipes produced by deep hole drilling and concluded that while it can be used to create very long pipes (up to $21 \mathrm{~m}$ ), there will always be an uneven distribution of wall thickness around the pipe circumference, due to difficulties in keeping the drill hole central over this length [27]. These issues are particularly prevalent for pipes of small diameters and wall thickness. However, a single-step process has a clear advantage from the cyclic nature of cold drawing and pilgering processes, and a scaled down version would be particularly promising if it could be achieved.

\subsection{Manufacturing summary}

The techniques employed in the manufacture of thin-walled pipes can be categorised as either methods well established for larger diameter pipes which have been scaled down (such as cold drawing or pilgering) or novel processes specially designed for thin-walled pipes (such as cold spray forming). When designing a manufacturing method for thin-walled pipes, there are unique challenges such as size effects on material behaviour, and how feasibly tools used in manufacture can be scaled down.

A summary of the ratio of the wall thickness $\left(t_{w}\right)$ to the outer diameter $\left(d_{o}\right)$ for the different manufacturing methods for steel pipes in the literature is presented in Figure 3. As can be seen, cold pilgering is the technique that is most often used in the production of thin-walled steel pipes, although it is well known that this approach can be scaled up to larger ratios if necessary.

\section{Joining methods for thin-walled pipes}

In addition to the pipe material, design and manufacturing method, the technique chosen to join pipes to each other or to other components is critical to the success of a cooling system as a whole. Several joining methods have been successfully used in thin-walled piping systems. In general, these fall into 3 categories:

- Fusion welding, where external heat is added generally with a filler material to promote a bond between two parts

- Solid-state welding, where frictional forces are used to generate heat and plasticise the material to form a joint

- Adhesive bonding where an adhesive is added between two parts and allowed to cure to form a joint

Mechanical joining, such as with bolts or other external fixtures, is not generally used in high pressure piping systems due to a lack of leak-tightness.

\subsection{Fusion welding}

Fusion welding processes are very common with thin-walled pipe connections and the most widely used joint is the soldered/brazed connection [28]. Soldering is based on heating and melting a filler material, which solidifies and forms a permanent connection between the two parts. Brazing is very similar to soldering; however, the melting point of the filler is over $450^{\circ} \mathrm{C}$ [29]. In both techniques, the filler material is often melted using a localised non-contact heat source such as a laser or an induction coil, which allow for fast ramp up rates of temperature and cooling rates after joining [30]. This is particularly advantageous as an increase in welding heat input can result in a HAZ as well as an increase in residual stresses in the weld area. The strength of a soldered joint is dependent on the relevant surface preparation, with rougher surfaces promoting penetration of molten solder and intensifying the diffusion $[29,31]$. The joint is also highly dependent upon the joint clearance or distance between parts; the optimal distance depends on the filler material and joint design. If properly designed and executed, soldered joints can be very effective; however, they are known to be particularly dependent on the skill of the operator.

Orbital tungsten inert gas (TIG) welding is another example of a popular technique for joining moderately thin-walled pipes. This method is now automated and produces reliable, leak tight welds $360^{\circ}$ around the pipe. The two most important factors to ensure a good joint are the control of the weld current and the travel speed of the electrode [32]. The automated nature of the process ensures that it is suitable for use in applications where reliability and leak tightness are critical, such as orbital plumb lines for satellites [33]. However, TIG-welded samples show low elongation in experimental 
Figure 3 Schematic of $t_{w} / d_{o}$ of steel pipes manufactured by various methods with nominal outer diameters highlighted

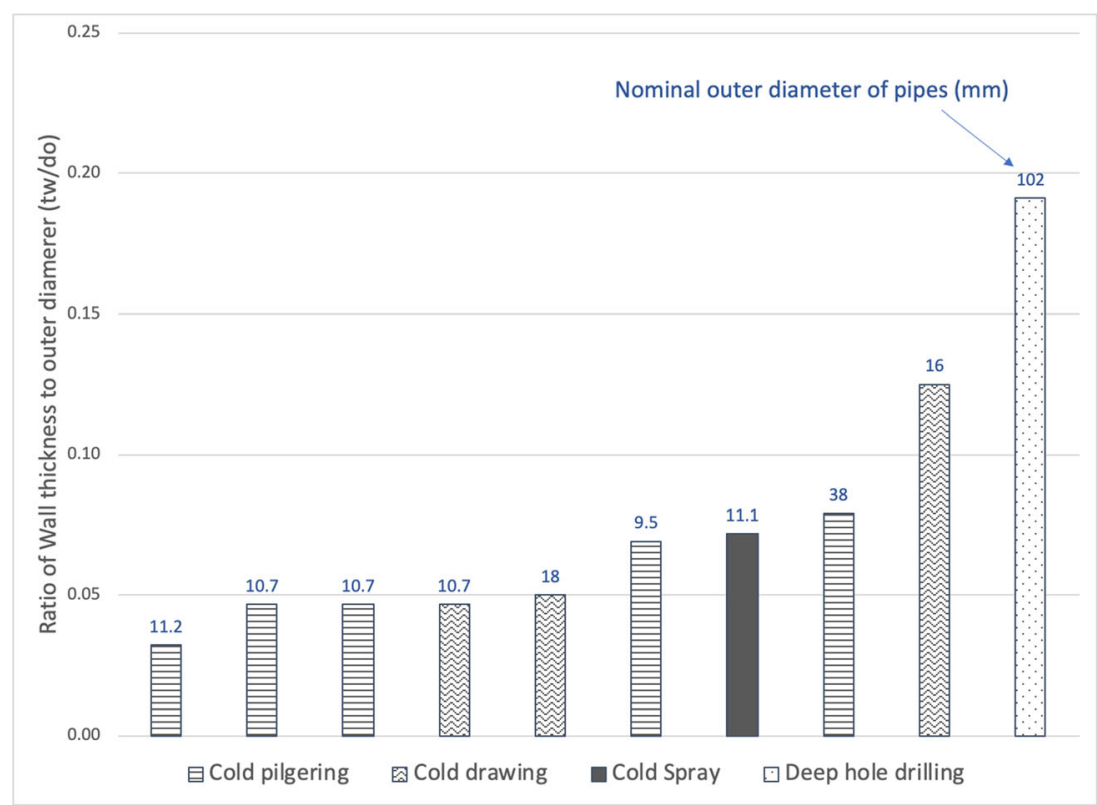

tests compared to the base metal and tend to fail in the HAZ. This failure mode is typically a demonstration of the heat affected zone around the weld which changes the microstructure and leads to residual stresses along the TIG fusion boundary. As a result, the design and welding parameters of a TIG joint need to be carefully considered. Additionally, TIG welding requires good access around the weld, which is often not possible in congested detector cooling systems.

Laser welding is an example of a fusion welding process which does not use a filler material. In heat conduction laser welding, the laser beam is applied to the surface of the material causing it to melt. However, this method is not suited to thin-walled pipes as it can damage the walls [34]. The other type of laser welding is deep penetration welding which is more commonly used for thin-walled pipes. This approach is based on using a laser to heat a material above its evaporation point, in order to produce a keyhole in which the laser beam is reflected many times to heat the material. This enables faster welding and deeper penetration than other welding methods for tubes [35]; however, there is a higher risk of defects such as porosity, where evaporated gases in the keyhole degas upon cooling [34]. A recent study by Zhang et al. [36] has highlighted that this type of porosity is currently the major barrier which needs to be overcome to increase use of this approach in joining thin-walled pipes. Enhanced characterisation through computed tomography and electron microscopy has significant potential to improve understanding of the location, size, distribution and shape of the porosity formed. Such insights would facilitate optimisation of the laser power and welding speed through enhanced simulation of the build process.

Finally, a more novel fusion technique used to join thin-walled pipes is microwave hybrid heating, as demonstrated by [37]. This is where a metallic powder is placed in between two pipes to be joined, and microwave radiation is used to melt the powder and thereby forms a joint. The metal powder is chosen such that the particle size is nearly equal to the penetration depth of the microwaves, to ensure that the energy does not just simply reflect back [38]. Figure 4 shows a schematic of the different stages of microwave hybrid heating.

Microwave hybrid heating is a unique process as using this type of radiation allows the heat to be generated internally in the powder molecules, before being transmitted outwards, and was pioneered by [37]. This ensures faster heating (and a smaller heat affected zone) than traditional methods, as demonstrated by [39] but also produces lower porosity joints due to the uniform heating of microwaves [40]. The approach can be used to join dissimilar materials and is particularly useful for joining copper as this material is difficult to join with other fusion techniques due to its high thermal conductivity [37]. One of the main challenges of the approach is the design of susceptor as shown in Figure 4. This device acts as the primary heat source and needs to be placed in the joint zone for localised heating.

In terms of limitations, microwave heating cannot typically be used for pipe end-to-end joining [38], and at present, only a limited number of materials have been joined using this approach [41]. Further investigations to assess the suitability of joining a broader range of conventional pipe materials using this approach would address this research gap and facilitate increased usage of this promising method. Dedicated analysis into the impact of production parameters on the joint characteristics and mechanical properties would also enhance understanding and modelling capability to facilitate joint performance optimisation. 


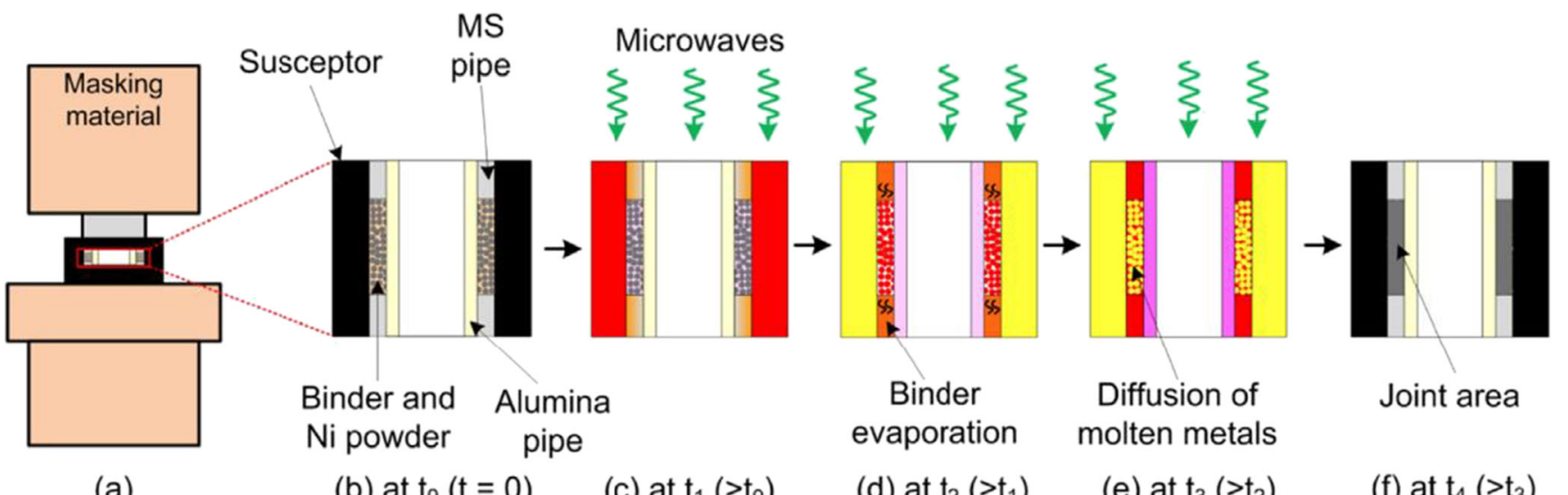

Figure 4 Schematic of the principles of microwave joining of metallic pipes at different stages [37]

\subsection{Solid-state joining}

The most common type of solid-state welding used in thin-walled pipes is end-to-end friction welding, where one pipe is continuously rotated and pushed onto a stationary pipe. This results in friction at the interface, which generates heat and thereby plasticises the two surfaces in order to form a bond. Kimura et al. [42] demonstrated that this technique can be used to successfully join steel pipes of $0.5-\mathrm{mm}$ wall thickness, although it was noted that low friction pressures are required for thin-walled pipes to prevent deformation. Variations in torque during the welding cycle are also important for reliable joint strength as demonstrated by an optimisation study by [43]. The time under friction is also important, with longer times (seconds to minutes) typically required for thin-walled pipes to allow in order to overcome the lower frictional pressures also noted by [43]. Friction welding is characterised by various advantages over fusion welding, including a high energy efficiency and a smaller heat affected zone (HAZ) as the heat generated during welding does not melt the material. Additionally, friction-welded joints are typically much more cost-effective than other joining methods.

Despite these benefits, a friction-welded joint often has limited tensile ductility in comparison to neighbouring bulk regions due to micro defects in the weld and/or regions of reduced hardness, as highlighted by [44]. Zhao et al. [45] have recently successfully demonstrated the joining of dissimilar copper and steel tubes using friction welding; however, it was highlighted that the weld zones can be brittle due to uneven and asymmetric diffusion of elements across the weld. It should be noted that the distribution and production of brittle phases induced by friction welding is poorly understood in thin-walled systems. This effect has the potential to significantly limit the applicability of this type of joint, in particular for high pressure of cyclically loaded applications. Further analysis through elemental characterisation methods such as energy dispersive spectroscopy and/or microscale testing such as nanoindentation would offer enhanced insight into the impact of production parameters and substrate materials. Similar studies have been used at larger length scales to optimise models of the joining procedure and thereby facilitate optimisation of joint performance [46]. Therefore, there is confidence that enhanced reliability can be achieved through replication of these types of study at the reduced length scales associated with thin-walled pipes.

Another common solid-state joining process for materials is adhesive bonding, although this method has seen a relatively low uptake within literature for thin-walled pipe joining. The small number of papers that was found in this review was based around pipe butt joints, where adhesives were either placed in between two pipe end surfaces [47] or where another material was impregnated with the adhesive and wound around the joint [48]. Adhesives are commonly used where there are dissimilar materials or materials are not suitable for fusion welding due to differences in melting point or thermal expansion. However, for high pressure thin-walled pipes for physics applications, this approach is not particularly useful for several reasons. Firstly, adhesive joints exhibit much lower strengths than their welded counterparts as demonstrated by a direct comparison study by [48]. Secondly, adhesives take a long time to cure, during which the pipes need to be rigidly clamped to ensure alignment [48], which may be challenging in the small spaces typically present within detector systems.

Finally, a more novel solid-state joining technique which has been demonstrated as suitable for thin-walled pipes is the magnetic pulse welding (MPW) [49]. This is a collision welding process which creates joints without the addition of heat, and instead uses Lorentz force to collide two parts at high velocities and pressures. Figure 5 shows a typical MPW set up, where the pipes are slightly overlapped with the inner pipe denoted the 'parent' and the outer pipe the 'flyer'. MPW has a short process time and a minimal temperature rise which leads to little to zero formation of intermetallics at the joint [51]. Shanthala and Sreenivasa [52] demonstrated that this technique is easily automated and the final product is consistent 
Figure 5 Schematic of MPW process [50]
During pulse

After pulse

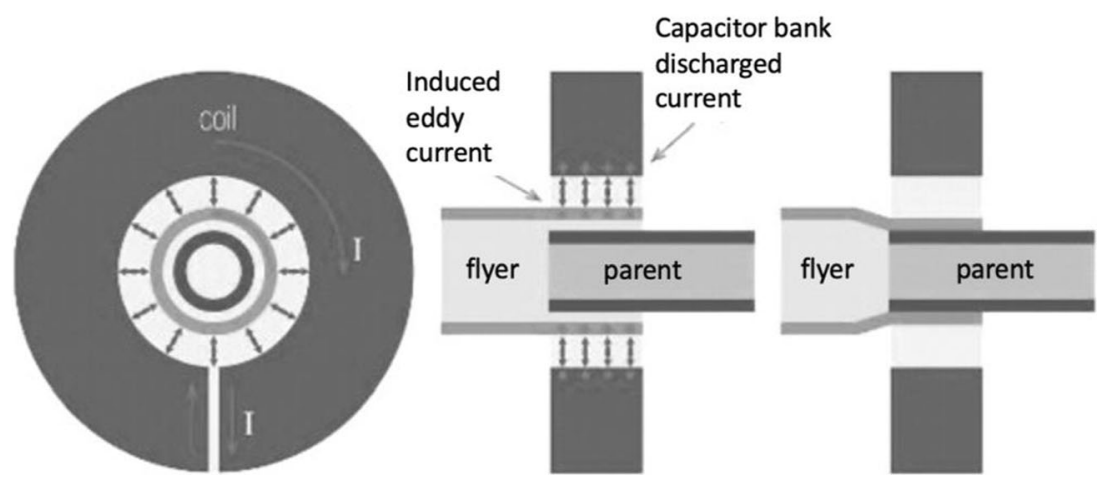

with exceptional tolerance and few surface defects. This approach has been used in aerospace push/pull rods for many years, as it produces tight, $360^{\circ}$ joints that can withstand many cyclic loads [53].

One of the main challenges of MPW is associated with the high velocities experienced by the parts, which can lead to unwanted distortions. In order to overcome this, inserts can be used within the parent pipe. These inserts are typically made from polyurethane to allow easy removal. Despite this, [49] demonstrated that thin-walled copper and steel pipes of between 1.5 and $2 \mathrm{~mm}$ wall thickness could be joined without the need of a supporting insert in the case where the wall thickness of the flyer was smaller than the parent.

In summary, MPW has significant potential for use in $\mathrm{CO}_{2}$ cooling systems. The authors feel that this area deserves significant future investigation for thin-walled pipes, particularly in the joining of glands to pipe ends where different materials are used. One of the main research gaps associated with this technique is the generation of residual stresses generated by MPW and the associated impact on the mechanical properties of the joint. However, preliminary studies of dissimilar material MPW using neutron diffraction have begun to reveal that residual stress distributions are dependent upon the differing material yield strengths and strain rates induced during the welding process [54]. In order to better understand these variables, along with other crucial parameters, further analysis is required to obtain characterise general trends. These insights can then be used to enhance numerical models for the stresses induced in the MPW process, which are already beginning to show promising results [55].

\subsection{Effect of materials on joining methods}

As outlined in Sections 4.1 and 4.2, the base material of the pipe heavily influences the choice of joining method which can be undertaken. This can be due to the melting temperatures of the substrate material, the wettability of solder on the material surface or the ductility/strength and ability to withstand joining techniques which require the addition of external forces to form the joint.

However, it is important to note that the choice of pipe material can strongly influence the strength and deformation behaviour of any joint, even when the joining technique stays the same.

Work is currently ongoing to investigate the effect of pipe materials and coatings on the performance of thin-walled pipes. In the study presented below, 316L stainless steel thin-walled pipes, with an outer diameter of $2.2 \mathrm{~mm}$, were soldered onto brass connectors. Each soldered connection was subjected to a tension test to destruction, with a strain rate of $1 \mathrm{~mm} / \mathrm{min}$. In order to increase the diffusion of the solder flux, the pipes were coated with a thin layer of nickel, and then a further layer of either copper or gold. The copper coating was approximately $10 \mu \mathrm{m}$ and the gold was approximately 5 $\mu \mathrm{m}$; however, it can clearly be seen from Figure 6 that the choice of coating severely affects the performance of the connections.

Figure 6 demonstrates that the force/displacement curves for the two sets of samples are very different, both in terms of maximum load achieved, and the behaviour of the joints during loading. The gold-coated samples achieved consistently lower strengths than the copper, with a much lower displacement to failure.

These results form part of a continuing piece of work, but the authors want to draw attention to the fact that material choices for the pipe and coating are critical for the success of a thin-walled pipe connection.

\subsection{Joining summary}

In order to summarise the current state of the literature, Figure 7 has been produced to show the ultimate tensile strengths (UTS) of steel pipes as a function of varying pipe wall thickness/outer diameter ratio. As demonstrated in the figure, the most common welding process for thin-walled steel pipes is fusion welding. It can also be seen that there is a wide 
Figure 6 Force/displacement curve of coated stainless steel soldered samples that were tension tested to destruction

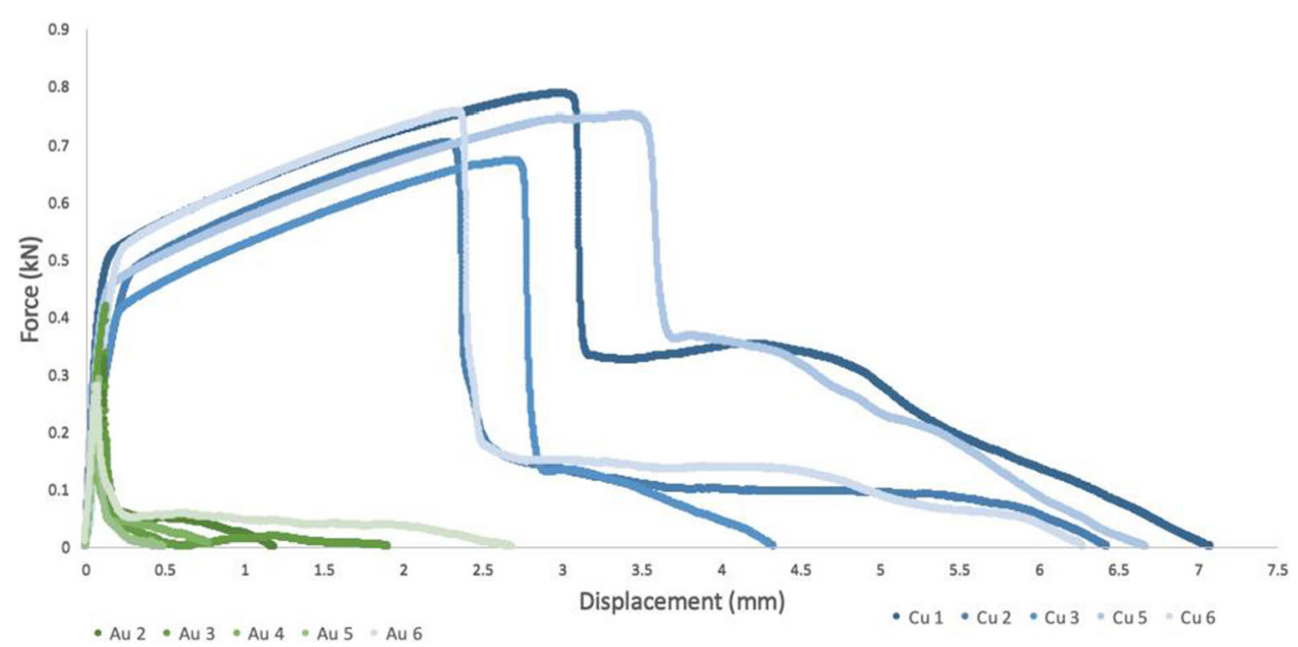

range of strengths within this category, depending on the fusion method applied. Friction welding is less common within literature, however, has consistently high strengths as opposed to adhesive bonding which consistently demonstrates low strengths. Interestingly, increasing the wall thickness/outer diameter ratio does not always increase the strength of the joint. This suggests that careful design can result in very high strengths for even a low $\mathrm{t}_{\mathrm{w}} / \mathrm{d}_{\mathrm{o}}$ ratio pipe system.

Table 2 presents a summary of all the joining techniques mentioned in this section. Their potential uses and key considerations are summarised as follows:

\section{Operational challenges}

As stated previously, applications which utilise thin-walled pipes generally operate at high pressures which creates significant challenges that must be considered in the design and selection of thin-walled pipes as demonstrated by [56, 57]. The stress analysis performed by (Keith, 2006) highlighted that the principal stresses which must be considered when designing a piping system are those that are sustained, cause expansion or are occasionally observed (for example during installation or an undesirable loading event).

As given in the standard [2], the hoop stress for a thin-walled pipe can be calculated using:

$S_{\mathrm{h}}=\frac{p d_{\mathrm{o}}}{2 t_{\min }}$

where $p$ is the internal pressure (MPa); $d_{\mathrm{o}}$ is the internal diameter of pipe (mm); $t_{\min }$ is the minimum wall thickness of pipe $(\mathrm{mm})$

Figure 8 shows a typical thin-walled pipe cross section with a nominal pressure of $100 \mathrm{bar}(10 \mathrm{MPa})$ that is representative of many high-pressure cooing systems incorporating thin-walled pipes.

Using Equation 1, $S_{\mathrm{h}}=110 \mathrm{MPa}$. For reference, the yield strength of $316 \mathrm{~L}$ stainless steel is $205 \mathrm{MPa}$ [58], which gives a safety factor of less than 2 for this design. This does not take
Figure 7 UTS against wall thickness/outer diameter ratio for experimentally tested steel pipes within literature

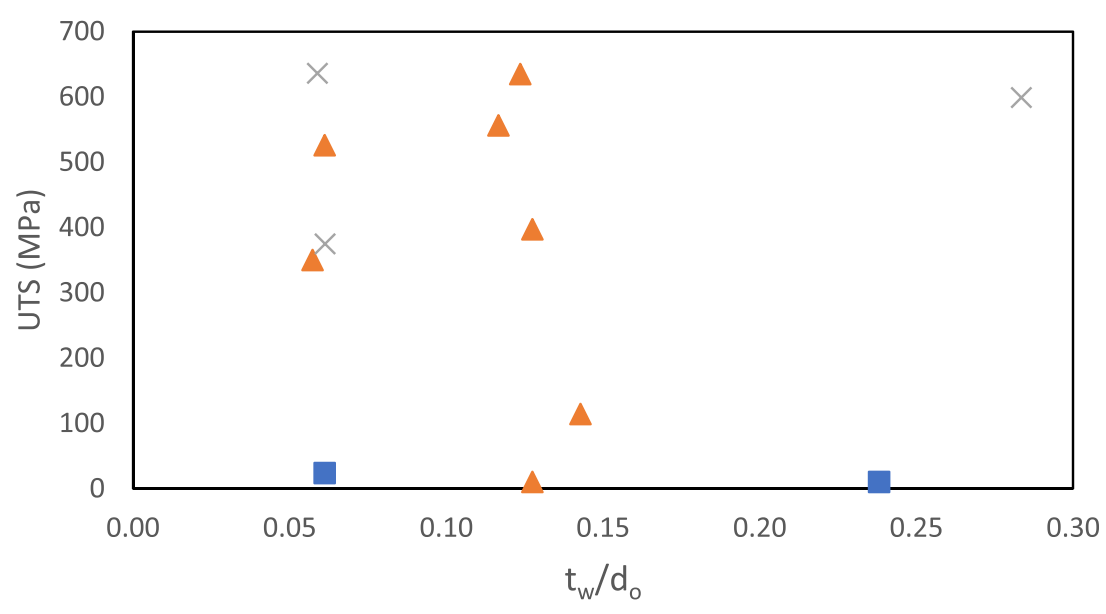

Adhesive $\triangle$ Fusion Welding $\times$ Solid State Welding 
Table 2 Tabular overview of strengths and weaknesses of different thin-walled joining techniques

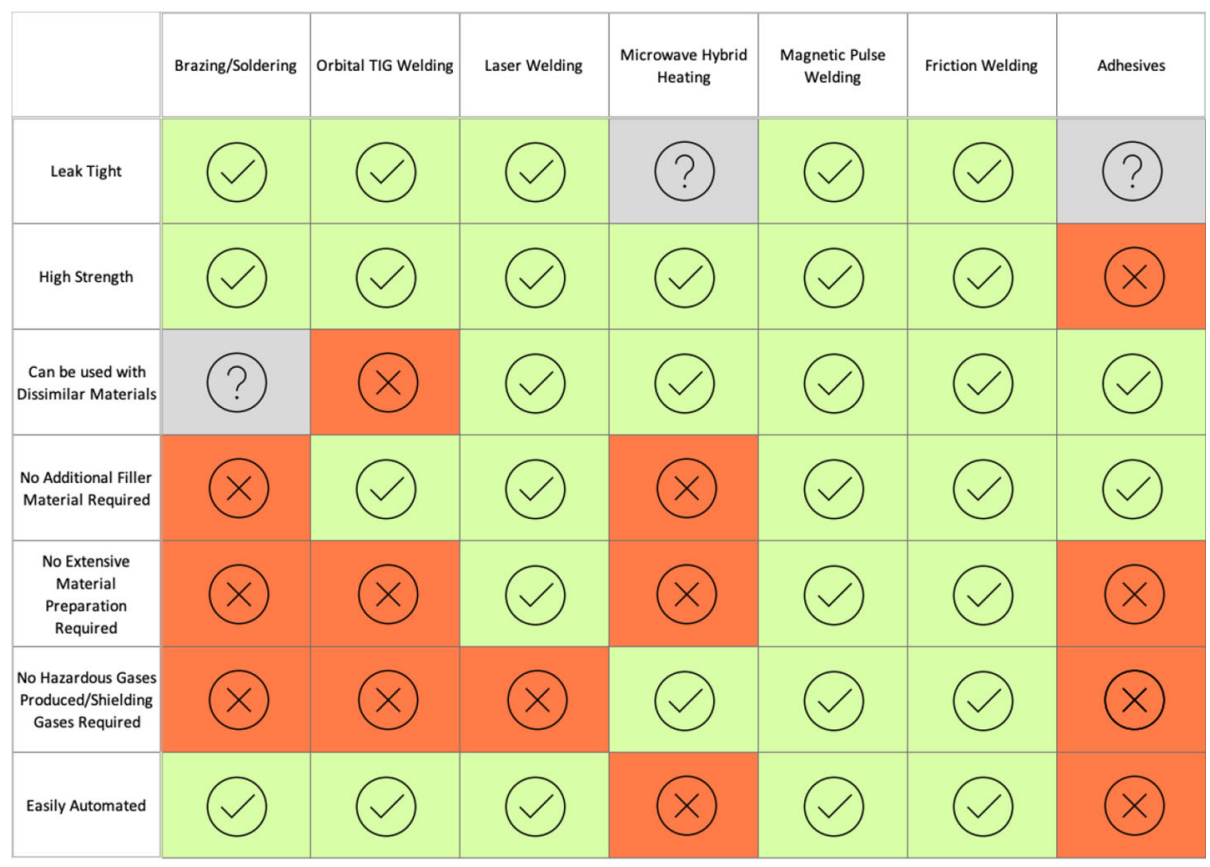

Key:

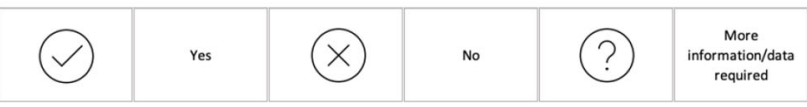

into account pressure tests before installation which are often executed at pressures in the range of 143bar to 186bar depending on the system.

For high pressure two-phase $\mathrm{CO}_{2}$ in particular, other loading requirements must be considered during the use of thin-walled pipes. For example, evaporative cooling and two-phase flow create complicated flow regimes, particularly within small diameter pipes as macroscale flow patterns cannot be generated, as demonstrated by [59]. In addition, the

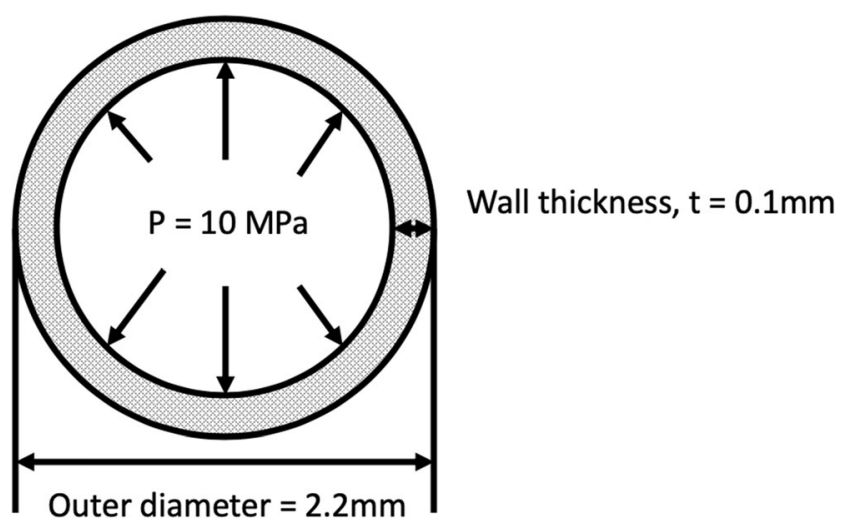

Figure 8 Cross section of typical thin-walled high pressure cooling pipe showing dimensions and loading change from one regime to another changes drastically as the size of the channel becomes very small. There are four primary flow regimes within a microchannel as shown in Figure 9, with several transition regimes or mixes of these primary regimes. These are the following:

- Bubbly flow - where the vapour is dispersed in the liquid in bubbles much smaller than the diameter of the pipe/channel

- Slug flow-where vapour is contained in elongated bubbles that approach the size of the pipe/channel

- Annular flow_-liquid film at pipe walls with vapour core

- Mist flow-liquid dispersed in droplets along a vapour phase

It is important to understand the flow regime the two-phase $\mathrm{CO}_{2}$ will experience in a system, as it can have a significant impact to the life, wear and operation of a cooling system. Guo et al. [60] state that mass transfer performance of a two-phase system is significantly affected by the flow distribution, and a uniform flow distribution is beneficial.

However, due to the nature of evaporative cooling, the liquid-vapour phase change generates random pressure 
Figure 9 Schematic of four primary flow regimes of twophase liquid/vapour mix in microchannels [50]



a) Bubbly flow



c) Annular flow

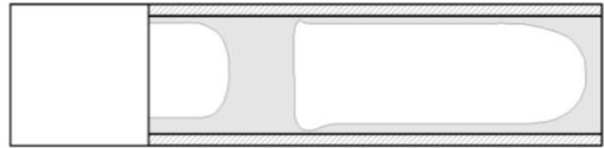

b) Slug flow

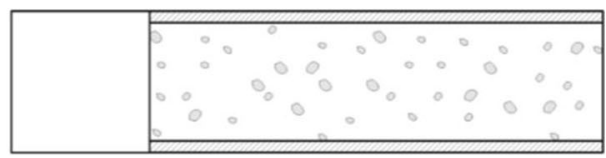

d) Mist flow oscillations in the fluid, which affects the life and wear of the microchannels. In particular, when the pressure of a liquid flow is reduced to lower than the fluid saturation pressure, cavitation begins. This generates bubbles in the fluid, which then collapse and generate high energy density jets which erode the inner surface of a pipe. Over a lifetime of a cooling system, this can be very damaging and cause significant wear. While cavitation in boiling $\mathrm{CO}_{2}$ cannot be totally avoided, it needs to be understood in order to mitigate its effect on the microchannels. Two-phase flow has been shown by [61] to cause very different pitting and wear in heat injection/rejection regions, with increased wear in rejection/condensation pipes.

Thome and Cioncolini [59] also note that as the size of the channel decreases, surface effects such as roughness and wettability become more important. The quality of the inner surfaces significantly affects the evaporation within the fluid and performance of the cooling system as a whole. The places where bubbles form is highly dependent on the surface roughness of the pipe wall, and therefore, operational parameters such as heat transfer coefficient are fundamentally linked to surface quality. The origin of bubble formation in evaporative cooling systems is a very large topic which is still the focus of significant experimental investigation and simulation. However, surface roughness cannot be ignored when designing such a cooling system as it can have significant and long-lasting impacts on performance and reliability.

\section{Future directions and uses for thin-walled pipes}

Thin-walled pipes are increasingly finding use in high-pressure $\mathrm{CO}_{2}$ cooling systems for high energy physics; however, it is clear that a number of other industries will also benefit from further research into the manufacture and joining of thin-walled pipes. These include (but are not limited to) the following:

1. Satellite propulsion systems. These systems often use thin-walled pipes as plumb lines which have very similar strength and loading requirements as those used in two-phase $\mathrm{CO}_{2}$ cooling as highlighted by $[32,33]$. As the use of satellite communications increases, with relatively low-cost Cube-Satellites now being offered by many different companies [62], it is clear that thin-walled pipes have an important role to play in future designs. Any advances in thin-walled pipe manufacture can therefore contribute a key value adding factor and a competitive advantage. In particular, the inability to perform maintenance and long expected lifetimes of these devices mirror the requirements of accelerator physics detector cooling.

2. High performance electronic devices. The mobile electronic community regularly make use of copper alloy tubing between 2 and $3 \mathrm{~mm}$ outer diameter and wall thickness between 0.35 and $0.60 \mathrm{~mm}$ for certain applications [63]. However, as handheld electronics get more advanced with higher energy requirements, and a shift towards sophisticated wearable technologies, the cooling requirements for such devices will increase. As such, the use of high-pressure, low-diameter tubing is on the rise and a comprehensive understanding of effective connection methods is crucial for widespread reliable use.

3. Refrigeration systems. Food refrigeration systems, both for household use and for larger scale applications (such as supermarkets and food-chain warehouses), are expected to increasingly move towards $\mathrm{CO}_{2}$ cooling systems in the future. $\mathrm{CO}_{2}$ is an attractive refrigerant as it is non-toxic, non-flammable and does not contribute to ozone depletion. Furthermore, many countries have created legislation to phase out fluorocarbons due to their negative environmental impact. While $\mathrm{CO}_{2}$ has many advantages over fluorocarbons (high latent heat of evaporation, lower viscosity and a higher heat transfer coefficient), it requires high pressure tubing (44-100 bar) [5]. These systems will require the mass production of reliable smaller diameter pipes, and the industry will benefit from further research into the effects of $\mathrm{CO}_{2}$ on the wear and lifetime of such pipes.

4. Medical uses. The most common use of thin-walled, small diameter pipes within medicine is undoubtedly the use of hollow needles for localised drug delivery, tissue sample removal and a large number of other procedures. Despite 
significant advances in medical procedures in recent time, the structure of medical needles has remained largely unchanged [64]. Attention is now being given to alternative needle design to increase accuracy, prevent deviation from the intended path and reduce trauma to healthy tissue [65]. Much of this focus is on alternative designs which deviate from the common 'straight' needle, into more curved shapes designed for a specific procedure. While curved pipes are not the specific focus of this review, the authors believe that any advances in the capabilities of manufacturing of thin-walled metallic pipes will also be of benefit to these designs

5. Nuclear power generation. The nuclear power industry has long utilised thin-walled pipes as fuel cladding tubes, with [66] and [67] both highlighting that cladding pipes typically have diameters between $0.38 \mathrm{~mm}$ and $0.90 \mathrm{~mm}$. Nuclear systems are often exposed to extreme loading conditions (stress, high temperatures, corrosion and radiation), and reliable manufacturing techniques are vital to ensure safety [68]. In particular, radiation effects can cause hardening and embrittlement of metallic crystalline structures [69] which slowly degrade their effectiveness over time. Enhanced manufacturing techniques will facilitate improved control of the microstructure of thin-walled cooling pipes, which is often a strength limiting factor in these components. As such, the development of novel techniques which can ensure precise microstructural control will be highly beneficial for this industry in future.

6. High precision scientific instruments. High quality pipes and connections which are both reliable and leak-tight are essential for a number of instruments such mass spectrometers, precise air-quality measurement devices and systems which allow detection of low volume gases produced from explosives or other illegal substances. Reliable manufacturing methods for very small diameter, thin-walled pipes and leak-tight joining methods will therefore provide a key value-adding factor for the manufacturers of such devices.

\section{Thin-walled pipes-knowledge gaps}

It is clear that with all this future potential for thin-walled pipes and connections, further advancements are required to optimise such designs, and to characterise the different manufacturing routes and materials that can be used. Throughout this review, several gaps in knowledge have been highlighted, including the following:

1. Further studies on the miniaturisation of manufacturing and joining methods that are well-established for larger pipe diameters would likely increase the uptake of small diameter, thin-walled pipes in industry. The major issue with adapting existing technologies is that thin-walled pipes are more likely to deform under the thermomechanical forces induced during manufacturing and joining. As such, to successfully utilise such technologies, the authors believe that both an enhanced understanding of the microstructural changes induced under such loading is required, in addition to the creation of higher precision machinery. One promising route appears to be the use of adaptive control combined with real time sensors which has significant potential to help miniaturise existing processes for the production and manufacture and joining of thin-walled pipes.

2. Solid-state joining techniques show great promise in the joining of different pipe materials, particularly in the case of MPW. In a physics accelerator context, this could be of great use in joining pipes to glands which are of different materials. However, the equipment used to produce these joints is typically cumbersome; a coil needs to be formed around the joint circumference to induce a current and achieve a successful joint. The use of this type of device is extremely difficult within an accelerator physics detector where spaces are tight and access is limited. For this reason, further research into refining these techniques for use in small spaces would be extremely beneficial in expanding their capabilities and use cases.

3. An improved understanding of the impact of material selection on thin-walled cooling pipe performance and connections are required. Several materials such as stainless steel and titanium are excellent candidates for the manufacture and design of thin-walled pipes; however, they can be difficult to join, particularly with fusion methods. Pipes with an extremely thin coating of another metal which can be more easily fusion welded have shown significant potential and are a route which is increasingly gaining interest. However, an enhanced understanding of the residual stresses and the quality of the interface between the coating and substrate pipe are required to ensure long-term reliability and success of this promising approach.

4. Another material effect which would benefit from further research is the repeatability of manufacturing processes and the detection of small faults/variations in materials. The limited material volumes associated with thin-walled pipes mean that very slight changes in material structure and composition can have a significant effect on performance. As such, specific studies into the use of non-destructive testing methods for the detection of residual stresses, microcracks and other faults with thin-walled pipes would benefit both the miniaturisation of manufacturing techniques and joint quality. There are a number of methods available for non-destructive testing 
on small length scales (Barkhausen effect, ultrasound, neutron diffraction and eddy-current methods); however, given the long aspect ratios of thin-walled pipes, further investigations into the suitability of these techniques for this application are warranted.

5. The effect of two-phase $\mathrm{CO}_{2}$ cooling on the performance of thin-walled pipes over their lifetime needs to be better understood. This includes specific attention to thermal fatigue behaviour when highly pressurised pipes are used over their service lifetime, and also the influence of wear and contaminants in the flow. As described in this review, two-phase $\mathrm{CO}_{2}$ can have a significant impact on the surface quality of the inner surfaces of pipes, but this is not well understood for the length scales present with such small-diameter, thin-walled pipes. It should be noted that the recent establishment of many $\mathrm{CO}_{2}$ cooling systems means that this avenue of investigation is in its infancy. However, the authors would like to highlight that the decommissioning of many of these systems offers a particularly promising avenue to improve understanding and this should be considered carefully by the wider community.

6. The types of systems described in this review, and the industries which could utilise thin-walled pipes in the near future, all require designs which are of high-strength and also highly reliable. Currently, there are only a few material choices which can meet these requirements, whilst simultaneously being able to be manufactured into the length scale and volumes required. However, it is widely known that faults induced by the manufacturing process can be critical to strength due to the small length scales of thin-walled pipes. In recent years, a number of micromechanical testing techniques have been developed which can be used to enhance existing understanding of the impact of varying production parameters on the failure of these types of systems. This can include the use of synchrotron radiation, focused ion beam (FIB) milling and nanoindentation, which can provide key insights at the microscale. It is the opinion of the authors that these techniques will prove critical in the understanding of loading on thin-walled pipes, and will be critical in the wider implementation of such designs.

7. Finally, the potential of novel seamless pipe manufacturing techniques need to be further investigated. This paper has described in detail the difficulties faces when using a well-established manufacturing method to produce small-diameter, thin-walled pipes. However, there is great potential in manufacturing methods specially designed for pipes of this scale, such as powder spraying or additive processes. The authors feel that further research into such novel techniques will increase the potential for optimised pipe performance.
8. One of the major knowledge gaps which is seen consistently across almost all of the thin-walled connection methods outlined in this study is the limited degree of experimental characterisation that has been performed. This is particularly true of the new and novel methods, but a review of the literature has revealed that even well-established methods are somewhat limited in terms of the number of investigations into the fundamental origins and impact of processing parameters on joint mechanical performance and tolerancing. The major reason for this has been associated with the accessibility and limited use of representative microscale testing, particularly in mechanical property variation. However, the last decade has seen widespread growth in terms of access to the equipment required to prepare samples at the micro to nano length scales required, such as focused ion beam-scanning electron microscopes (FIB-SEMs), and the microscale actuation/loading systems, such as nanoindenters, required for this type of analysis. In addition, improved access to high-resolution non-destructive methods such as Raman spectroscopy, computed tomography and synchrotron characterisation means that these approaches are becoming more mainstream. These enhanced capabilities will facilitate future investigations into the underlying characteristics of thin-walled cooling connections and impact of production parameters on joint performance. Such insights are essential in establishing reliable and representative models to facilitate optimisation of joint manufacturing techniques. For example, an improved understanding of the impact of pulse duration, energy, and dwell time on the microscale variations in residual stress generated by MPW are expected to lead to a substantial increase in joint strength and fatigue life. This methodology has significant potential to tackle the broad range of limitations and challenges identified in this paper. As a result, it is the authors' opinion that substantial research efforts and capital investment are required to ensure that the next generation of thin-walled joining techniques can achieve the demanding performance requirements expected in future.

\section{Conclusions}

In this work, the role of thin-walled metallic pipes and connections has been outlined in relation to their use for high pressure cooling systems. An extensive literature survey has been undertaken to describe the manufacturing requirements and joining techniques which has revealed that seamless tubes are the best choice for thin-walled pipes. Currently, cold forming techniques appear to have the most potential for the small diameters required in these systems, although more novel techniques such as cold spray forming could prove a viable alternative. 
Soldered/brazed connections are the most common joining techniques for thin-walled pipes. However, it is clear that further investigations are required to better understand the impact of material choice on joint strength. Other joining techniques such as orbital TIG and friction welding have also significant potential in the area of two-phase $\mathrm{CO}_{2}$ cooling systems due to their high strengths and leak tightness. The key parameters that affect the operation and reliability of thin-walled pipes when used for two-phase $\mathrm{CO}_{2}$ cooling are the pressure of the $\mathrm{CO}_{2}$ fluid within the pipes, the temperature at which the cooling system operates and finally the surface quality and roughness of the inner pipe surface.

Author contribution Sophie A. M. McNair: investigation, formal analysis, writing - original draft; Alborz Shokrani Chaharsooghi: conceptualisation , resources; Mauro Carnevale: conceptualisation, resources; Andrew Rhead: supervision, writing-review and editing; Antti Onnela: conceptualisation, writing - review and editing; Jerome Daguin: conceptualisation, resources; Kamil Cichy: conceptualisation; Hans Postema: conceptualisation; Nicola Bacchetta: conceptualisation; Thomas French: conceptualisation; and Alexander J. G. Lunt: supervision, writing — review and editing

Funding This work was supported by the Engineering and Physical Sciences Research Council (ESPRC).

Data availability No data/code has been presented in this paper; all references have been included where material has been used/referenced.

\section{Declarations}

Ethics approval N/A - article will not be submitted to a life science journal and no studies involving humans and/or animals

Consent to participate N/A - article will not be submitted to a life science journal and no studies involving humans and/or animals.

Consent to publish N/A - article will not be submitted to a life science journal and no studies involving humans and/or animals.

Conflict of interest The authors declare no competing interests.

Open Access This article is licensed under a Creative Commons Attribution 4.0 International License, which permits use, sharing, adaptation, distribution and reproduction in any medium or format, as long as you give appropriate credit to the original author(s) and the source, provide a link to the Creative Commons licence, and indicate if changes were made. The images or other third party material in this article are included in the article's Creative Commons licence, unless indicated otherwise in a credit line to the material. If material is not included in the article's Creative Commons licence and your intended use is not permitted by statutory regulation or exceeds the permitted use, you will need to obtain permission directly from the copyright holder. To view a copy of this licence, visit http://creativecommons.org/licenses/by/4.0/.

\section{References}

1. Hartl C (2019) Review on advances in metal micro-tube forming. Metals 9:542. https://doi.org/10.3390/met9050542

2. PD 8010-1:2015: Pipeline systems. Steel pipelines on land. Code of practice 2015.

3. Diaby AT, Byrne P, Maré T (2019) Simulation of heat pumps for simultaneous heating and cooling using CO 2 Simulation de pompes à chaleur pour chauffage et refroidissement simultanés au CO 2. International Journal of Refrigeration 106:616-627. https:// doi.org/10.1016/j.ijrefrig.2019.03.010

4. Daguin J, Arndt K, Bertl W, Noite J, Petagna P, Postema H et al (2012) Evaporative CO 2 cooling system for the upgrade of the CMS pixel detector at CERN. InterSociety Conference on Thermal and Thermomechanical Phenomena in Electronic Systems, ITHERM, pp 723-731. https://doi.org/10.1109/ ITHERM.2012.6231499

5. Benhadid-Dib S, Benzaoui A. Refrigerants and their environmental impact substitution of hydro chlorofluorocarbon HCFC and HFC hydro fluorocarbon. Search for an adequate refrigerant. Energy Procedia, vol. 18, Elsevier BV; 2012, p. 807-16. 10.1016/j. egypro.2012.05.096.

6. CERN EUROPEAN ORGANIZATION NUCLEAR RESEARCH, NIKHEF, VERLAAT B. Mini cooling system and method for accurate temperature control. JP6087359B2, 2017.

7. Verlaat B, Nikhef, CERN-European Organization Nuclear Research. COMPACT COOLING SYSTEM AND METHOD FOR ACCURATE TEMPERATURE CONTROL. US 20140230471 A1, 2014.

8. Senes E, Emery J, Fraser MA, Guerrero Ollacarizqueta A, Huschauer A, Roncarolo F, Sirvent JL, Skowronski P, Tecker F, Forte V (2019) Transverse emittance measurement in the CERN Proton Synchrotron in view of beam production for the HighLuminosity LHC. Journal of Physics: Conference Series 1350: 012087. https://doi.org/10.1088/1742-6596/1350/1/012087

9. Ballarino A, Hopkins SC, Bordini B, Richter D, Tommasini D, Bottura L, Benedikt M, Sugano M, Ogitsu T, Kawashima S, Saito K, Fukumoto Y, Sakamoto H, Shimizu H, Pantsyrny V, Abdyukhanov I, Shlyakov M, Zernov S, Buta F et al (2019) The CERN FCC conductor development program: a worldwide effort for the future generation of high-field magnets. IEEE Transactions on Applied Superconductivity 29:1-9. https://doi.org/10.1109/ TASC.2019.2896469

10. Rodriguez Mateos F, Balampekou S, Carrillo D, Dahlerup-Petersen K, Favre M, Mourao J, Panev B (2018) Design and manufacturing of the first industrial-grade CLIQ units for the protection of superconducting magnets for the high-luminosity LHC project at CERN. IEEE Transactions on Applied Superconductivity 28:1-4. https://doi.org/10.1109/TASC.2018.2794473

11. Korolyov P v, Puzina YY, Chakravarty A, Rane T, Klebaner A. PIP-II Cryogenic System and the evolution of Superfluid Helium Cryogenic Plant Specifications 2017. 10.1088/1757-899X/278/1/ 012092.

12. Shiltsev V (n.d.) Fermilab proton accelerator complex status and improvement plans. In: Fermilab Proton Accelerator Complex Status and Improvement Plans

13. Klein K, Abbaneo D, Alexander J, Azzi P, Brondolin E, Canepa A, et al. The Phase-2 Upgrade of the CMS Tracker Technical Design Report CMS Collaboration 2 Editor Chapter editors Cover Design. 2017.

14. Dierlamm A, The CMS (2019) Outer Tracker Upgrade for the HLLHC. Nuclear Instruments and Methods in Physics Research, Section A: Accelerators, Spectrometers, Detectors and Associated Equipment 924:256-261. https://doi.org/10.1016/j.nima.2018.09. 144 
15. Parilák L', Burik P, Bella P, Mojžiš M (2019) Kejzlar P. Evolution of deformation texture in cold drawing of steel tubes using EBSD analysis and FEM simulation 461. https://doi.org/10.1088/1757899X/461/1/012010

16. Abe H, Furugen $M(2012)$ Method of evaluating workability in cold pilgering. Journal of Materials Processing Technology 212:16871693. https://doi.org/10.1016/j.jmatprotec.2012.03.012

17. Karanjule DB, Bhamare SS, Rao TH. Microstructure, property changes and characterization for st 35 steel material during multiple pass cold drawing process of seamless tubes. vol. 5. 2018.

18. Akchurin RZ, Bogatov AA, Salikhyanov DR, Ovchinnikov AS (2019) DEVELOPMENT AND INTRODUCTION OF TECHNOLOGY AND EQUIPMENT FOR MULTIPLE DRAWING OF COPPER ALLOY THIN-WALLED TUBE ON A LONG MOVABLE MANDREL WITHOUT INTERMEDIATE HEAT TREATMENT. Translated from Metallurg 62:61-66. https://doi.org/10.1007/s11015-019-00751-9

19. Aleksandrovich BA, Rinatovich D (2018) Sergeevich OA. Improvement of manufacturing technology for thin-walled pipes made of copper alloys 918:140-144. https://doi.org/10.4028/ www.scientific.net/MSF.918.140

20. Maier B, Lenling M, Yeom H, Johnson G, Maloy S, Sridharan K (2019) A novel approach for manufacturing oxide dispersion strengthened (ODS) steel cladding tubes using cold spray technology. Nuclear Engineering and Technology 51:1069-1074. https:// doi.org/10.1016/j.net.2019.01.015

21. Toribio J, Ovejero E (1997) Effect of cold drawing on microstructure and corrosion performance of high-strength steel. Mechanics Time-Dependent Materials 1:307-319. https://doi.org/10.1023/A: 1009714222132

22. Gaillac A, Ly C. Optimized manufacture of nuclear fuel cladding tubes by FEA of hot extrusion and cold pilgering processes. AIP Conference Proceedings, vol. 1960, American Institute of Physics Inc.; 2018, p. 030005. 10.1063/1.5034848

23. Abe H, Iwamoto T, Yamamoto Y, Nishida S, Komatsu R (2016) Dimensional accuracy of tubes in cold pilgering. Journal of Materials Processing Technology 231:277-287. https://doi.org/10. 1016/j.jmatprotec.2016.01.001

24. Dai J, Li W, Chu Z (2020) Microstructure evolution of cold pilgering stainless steel tubes. Advances in Materials Science and Engineering 2020:1-8. https://doi.org/10.1155/2020/3678980

25. Courtin L, Urvoy S, Bossu D, Bosonnet S, Tabarant M, Kedjar B et al (2015) Comparison of 15Cr-15Ni Austenitic Steel Cladding Tubes Obtained by HPTR Cold Pilgering or by Cold Drawing. In: Comparison of $15 \mathrm{Cr}-15 \mathrm{Ni}$ austenitic steel cladding tubes obtained by HPTR cold pilgering or by cold drawing. https://doi.org/10. 4028/www.scientific.net/KEM.651-653.38ї

26. Mohamed AS, Laban O, Tarlochan F, al Khatib SE, Matar MS, Mahdi E. Experimental analysis of additively manufactured thinwalled heat-treated circular tubes with slits using AlSi10Mg alloy by quasi-static axial crushing test 2019. 10.1016/j.tws.2019.02.022.

27. Maderbacher H, Pölzl M. Deep-hole-drilling of high pressure tubes - process stability and the influence of eccentricity on autofrettage and heat transfer. American Society of Mechanical Engineers, Pressure Vessels and Piping Division (Publication) PVP, vol. 5, American Society of Mechanical Engineers (ASME); 2017. 10.1115/PVP2017-65652.

28. Behulova M, Vrtiel Š, Nagy M (2019) Induction brazing of thinwalled pipes from AISI 304 steel using copper-based solder. IOP Conference Series: Materials Science and Engineering 465:12001. https://doi.org/10.1088/1757-899X/465/1/012001

29. Hebda M, Kaczor P, Miernik K. Vacuum brazing of stainless steel depending on the surface preparation method and temperature of the process. Archives of Metallurgy and Materials 2019;64:5-11. 10.24425/amm.2019.126210
30. Nishikawa H, Iwata N (2015) Formation and growth of intermetallic compound layers at the interface during laser soldering using Sn$\mathrm{Ag} \mathrm{Cu}$ solder on a $\mathrm{Cu}$ Pad. Journal of Materials Processing Technology 215:6-11. https://doi.org/10.1016/j.jmatprotec.2014. 08.007

31. Amirnasiri A, Parvin N, Mahdi \&, Haghshenas S. Investigation of surface roughness parameter in dissimilar diffusion brazing of WCCo to AISI 4145 Steel. \# International Institute of Welding 2019. 10.1007/s40194-019-00778-1.

32. Karthikeyan M, Vallayil NA, Naukan R, Narayan R, Sudhakar P. Orbital TIG welding process parameter optimization using design of experiment for satellite application. International Journal of Performability Engineering 2016;12:155. 10.23940/IJPE.16.2. P155.MAG.

33. Karthikeyan M, Naikan VNA, Narayan R. Orbital TIG Welding and Evaluating Methods of Propulsion Feed Lines for Satellites. vol. 20. 2017.

34. Heinen P, Wu H, Olowinsky A, Gillner A (2014) Helium-tight laser beam welding of aluminum with brillant laser beam radiation. Physics Procedia 56:554-565. https://doi.org/10.1016/j.phpro. 2014.08.043

35. Vänskä M (2011) Salminen A. Laser welding of stainless steel selfsteering tube-to-tube joints with oscillating mirror 226:632-640. https://doi.org/10.1177/0954405411425114

36. Zhang LJ, Liu JZ, Pei JY, Ning J, Zhang LL, Long J, Zhang GF, Zhang JX, Na SJ (May 2019) Effects of power modulation, multipass remelting and $\mathrm{Zr}$ addition upon porosity defects in laser seal welding of end plug to thin-walled molybdenum alloy. J. Manuf. Process. 41:197-207

37. Srinath M, Kumar Sharma A (2011) Kumar P. A new approach to joining of bulk copper using microwave energy 32:2685-2694. https://doi.org/10.1016/j.matdes.2011.01.023

38. Gamit D, Mishra RR, Sharma AK (2017) Joining of mild steel pipes using microwave hybrid heating at $2.45 \mathrm{GHz}$ and joint characterization. Journal of Manufacturing Processes 27:158-168. https://doi. org/10.1016/j.jmapro.2017.04.028

39. Tamang S, S A. JOINING OF CU TO SS304 BY MICROWAVE HYBRID HEATING WITH NI AN INTERLAYER. Proceedings 17th International Conference on Microwave and High Frequency Heating, Universitat Politècnica de València; 2019, p. 98-104.

40. Singh S, Singh P, Gupta D, Jain V, Kumar R, Kaushal S (2019) Development and characterization of microwave processed cast iron joint. Engineering Science and Technology, an International Journal 22:569-577. https://doi.org/10.1016/j.jestch.2018.10.012

41. Sahota DS, Bansal A, Kumar V (Jan. 2021) Application of microwave in welding of metallic materials - A review. Mater. Today Proc. 43:466-470

42. Kimura M, Ichihara A, Kusaka M, Kaizu K (2012) Joint properties and their improvement of AISI $310 \mathrm{~S}$ austenitic stainless steel thin walled circular pipe friction welded joint. In: Joint properties and their improvement of AISI $310 \mathrm{~S}$ austenitic stainless steel thin walled circular pipe friction welded joint. https://doi.org/10.1016/ j.matdes.2012.02.006

43. Balta B, Arici AA, Yilmaz M (2016) Optimization of process parameters for friction weld steel tube to forging joints. Materials and Design 103:209-222. https://doi.org/10.1016/j.matdes.2016.04. 072

44. Wang M, Zhao S, Wang W, Li Q, Luo GN (2019) Preliminary results of $\mathrm{CuCrZr} / 316 \mathrm{~L}$ tube-to-tube junctions fabricated with rotary friction welding. Fusion Engineering and Design 148:111275. https://doi.org/10.1016/j.fusengdes.2019.111275

45. Zhao S, Wang M, Kou S, Jia Z, Wang W, Li Q, Luo GN (Sep. 2020) Realization of ODS-Cu/T91 Tube-to-tube Joining with Rotary Friction Welding. Fusion Eng. Des. 158:111699 
46. Geng P, Qin G, Zhou J (Jan. 2020) A computational modeling of fully friction contact-interaction in linear friction welding of $\mathrm{Ni}$ based superalloys. Mater. Des. 185:108244

47. Rudawska A, Wahab A (2019) Müller M. Effect of ageing process on mechanical properties of adhesive tubular butt joints in aqueous environment 96:102466. https://doi.org/10.1016/j.ijadhadh.2019. 102466

48. Mishra A, Singh S, Kumar R (2018) Mital A. Natural fiber based adhesive butt joints as a replacement to gas welded butt joints for thin tubes: an experimental study 404. https://oi.org/10.1088/ 1757-899X/404/1/012024

49. Lueg-Althoff J, Bellmann J, Hahn M, Schulze S, Gies S (2019) Tekkaya AE, et al. Joining dissimilar thin-walled tubes by Magnetic Pulse Welding 279:116562. https://doi.org/10.1016/j. jmatprotec.2019.116562

50. Ben-Artzy A, Stern A, Frage N, Shribman V, Sadot O (2010) Wave formation mechanism in magnetic pulse welding. International Journal of Impact Engineering 37:397-404. https://doi.org/10. 1016/j.jimpeng.2009.07.008

51. Shanthala K, Sreenivasa TN, Choudhury H, Dond S, Sharma A (2018) Analytical, numerical and experimental study on joining of aluminium tube to dissimilar steel rods by electro magnetic pulse force. Journal of Mechanical Science and Technology 32:17251732. https://doi.org/10.1007/s12206-018-0328-0

52. Shanthala K (2016) Sreenivasa TN. Review on electromagnetic welding of dissimilar materials 11:363-373. https://doi.org/10. 1007/s11465-016-0375-0

53. EMF Technology in the Aerospace Industry n.d. http://www. elmaginc.com/emf-technology-in-aerospace ().

54. Avettand-Fènoël M-N, Sapanathan T, Pirling T, Racineux G, Simar A, Drezet J-M (Aug. 2021) Investigation of residual stresses in planar dissimilar magnetic pulse welds by neutron diffraction. J. Manuf. Process. 68:1758-1766

55. Li JS, Sapanathan T, Raoelison RN, Hou YL, Simar A, Rachik M (Oct. 2021) On the complete interface development of Al/Cu magnetic pulse welding via experimental characterizations and multiphysics numerical simulations. J. Mater. Process. Technol. 296:117185

56. Tropea P, Daguin J, Petagna P, Postema H, Verlaat B, Zwalinski L (2016) CO 2 evaporative cooling: the future for tracking detector thermal management. Nuclear Instruments and Methods in Physics Research, Section A: Accelerators, Spectrometers, Detectors and Associated Equipment 824:473-475. https://doi.org/10.1016/j. nima.2015.08.052

57. Bai Qiang BY (2014) Subsea Pipeline Design, Analysis, and Installation. Elsevier
58. ASM Material Data Sheet n.d. http://asm.matweb.com/search/ SpecificMaterial.asp?bassnum=MQ316Q ().

59. Thome J, Cioncolini A (2015) Two-Phase Flow Pattern Maps for Microchannels. Two-Phase Flow Pattern Maps for Microchannels: 47-84. https://doi.org/10.1142/97898146232160020

60. Guo R, Fu T, Zhu C (2018) Yin Y, Ma Y. The effect of flow distribution on mass transfer of gas-liquid two-phase flow in two parallelized microchannels in a microfluidic loop 130:266-273. https://doi.org/10.1016/j.ijheatmasstransfer.2018.10.078

61. Cai SQ (2019) Cavitation occurring in capillary tubes. Physics Letters, Section A: General, Atomic and Solid State Physics 383: 509-513. https://doi.org/10.1016/j.physleta.2018.11.026

62. Tummala AR, Dutta A (2017) An Overview of Cube-Satellite Propulsion Technologies and Trends. Aerospace 4. https://doi.org/ 10.3390/aerospace 4040058

63. Shioga T, Mizuno Y, Nagano H (2020) Operating characteristics of a new ultra-thin loop heat pipe. International Journal of Heat and Mass Transfer 151:119436. https://doi.org/10.1016/j. ijheatmasstransfer.2020.119436

64. Padasdao B, Konh B (2020) Shape Memory Alloy Actuators in an Active Needle-Modeling, Precise Assembly, and Performance Evaluation. Journal of Manufacturing Science and Engineering 143. https://doi.org/10.1115/1.4047737

65. Scali M, Pusch TP, Breedveld P, Dodou D (2017) Needle-like instruments for steering through solid organs: a review of the scientific and patent literature. Proceedings of the Institution of Mechanical Engineers Part H, Journal of Engineering in Medicine 231:250-265. https://doi.org/10.1177/0954411916672149

66. Samal MK (2011) Sanyal G. A load-separation technique to evaluate crack growth and fracture resistance behaviour of thin-walled axially cracked tubular specimens 226:1447-1461. https://doi.org/ 10.1177/0954406211424978

67. Terrani KA (2018) Accident tolerant fuel cladding development: promise, status, and challenges. Journal of Nuclear Materials 501: 13-30. https://doi.org/10.1016/j.jnucmat.2017.12.043

68. Zinkle SJ, Was GS (2013) Materials challenges in nuclear energy. Acta Materialia 61:735-758. https://doi.org/10.1016/j.actamat. 2012.11.004

69. Xiao X, Terentyev D, Chu H, Duan H (2020) Theoretical models for irradiation hardening and embrittlement in nuclear structural materials: a review and perspective. Acta Mechanica Sinica 36: 397-411. https://doi.org/10.1007/s10409-020-00931-w

Publisher's note Springer Nature remains neutral with regard to jurisdictional claims in published maps and institutional affiliations. 